\title{
Experimental evaluation of changes in strain under compressive fatigue
}

\section{loading of brick masonry}

\author{
I.S. Koltsida ${ }^{\mathrm{a}, 1}$, A.K. Tomor ${ }^{\mathrm{a}}$, C.A. Booth ${ }^{\mathrm{a}}$
}

${ }^{a}$ Faculty of Environment and Technology, University of the West of England, Frenchay Campus, Coldharbour Lane,

\section{ABSTRACT}

11 Assessing the long-term performance of masonry structures and their response to increased loading 12 conditions are critical to safety and maintenance. A series of laboratory tests have been carried out 13 on brick masonry to assess its performance under long-term fatigue loading. The relationship between 14 stress levels and number of cycles to failure was identified under compressive loading, together with 15 stress-strain evolution at various stress levels. Strain evolution shows distinctive characteristics for 16 the three stages of deterioration and increased strain for increased number of cycles. Experimental 17 results provide useful data for developing analytical prediction models for the fatigue deterioration 18 of masonry structures.

19 Keywords: Brick Masonry, Fatigue, Strain Evolution, Stress-Strain curves, SN curves 


\section{1. Introduction}

22 The longest standing bridges around the world are

23 masonry arch bridges, representing around $40 \%$ of

24 the highway, railway and waterway bridge

25 infrastructure in Europe [1]. Due to their age and

26 constantly increasing weight, speed and density of

27 traffic, their assessment and maintenance are

28 becoming increasingly important to ensure their

29 continued safe performance.

30 High-cycle fatigue loading experienced over 100+

31 years of service life can lead to significant changes

32 on the material level and deterioration below

33 serviceability or ultimate failure load [2].

34 Identifying the rate of fatigue deterioration and

35 changes in the material properties for masonry are

36 necessary to enable improved assessment of load

37 capacity, remaining service life, optimising traffic

38 loading and planning maintenance works.

39 Limited data is however available for assessing the

40 fatigue capacity of masonry structures. Some

41 experimental data is available on $\mathrm{SN}$ curves (stress

42 vs. number of cycles) for masonry under fatigue

43 loading (Abrams et al., 1985; Clark, 1994; Ronca

44 et al. 2004; Roberts et al., 2006; Tomor \&

45 Verstrynge, 2013; Tomor et al., 2013) but minimal
46 information has been presented on the evolution of

47 strain under fatigue deterioration.

48 Abrams et al. [3] performed experimental test 49 series on brickwork prisms to investigate the 50 mechanics of masonry under cyclic compressive

51 stress. Abrams et al. concluded that cyclic loading

52 leads to gradual reduction in the compressive

53 strength of masonry and that the rate of reduction

54 is a function of the mortar strength, amplitude and

55 number of cycles. Greater cyclic stress levels and

56 stronger mortars accelerate deterioration. Clark [4]

57 conducted similar experiments and proposed SN

58 curves for dry and wet masonry, suggesting a

59 fatigue limit for dry brick masonry around $\sim 50 \%$ of

60 its quasi-static compressive strength.

61 Roberts et al. [5] defined a lower bound fatigue

62 strength for dry, submerged and wet brick masonry

63 based on a series of quasi-static and high cycle

64 fatigue tests on brick masonry (Equation 1.1).

$$
F(S)=\frac{\left(\Delta \sigma \sigma_{\max }\right)^{0.5}}{f_{C}}=0.7-0.05 \log N \quad 1.1
$$

65 Where $F(S)$ is the function of the induced stress, $\Delta \sigma$ 66 is the stress range, $\sigma_{\max }$ is the maximum stress, $\mathrm{f}_{\mathrm{c}}$ is

67 the quasi-static compressive strength of masonry 68 and $\mathrm{N}$ is the number of load cycles. 
69 Casas [2] proposed a probability-based fatigue

70 model for brick masonry under compression with

71 different defined confidence levels based on the

72 experimental data reported by Roberts et al. [5]

73 (Equation 1.2).

$$
S_{\max }=A \times N^{-B(1-R)}
$$

74 Where $S_{\max }$ is the ratio of the maximum loading

75 stress to the quasi-static compressive strength, $\mathrm{N}$ is

76 the number of cycles to failure and $\mathrm{R}$ is the ratio of

77 the minimum stress to the maximum stress

$78 \sigma_{\min } / \sigma_{\max }$. Coefficients A and B depend on the value

79 of the survival function and were calculated by

80 Casas [2].

81 Tomor and Verstrynge [6] proposed a joined

82 fatigue-creep deterioration model. A probabilistic

83 fatigue model was suggested by adapting Casas'

84 [7] model and introducing a correction factor C,

85 allowing the interaction between the creep and

86 fatigue phenomena to be taken into account and

87 adjusting the slope of the SN curve (Equation 1.3).

$$
S_{\max }=A \cdot N^{-B(1-C \cdot R)}
$$

88 Where $S_{\max }$ is the ratio of the maximum stress to

89 the average compressive strength $\left(S_{\max }=\sigma_{\text {Max }} / f_{c}\right), 114$ Carpinteri et al. [9] performed a series of quasi-

$90 \mathrm{~N}$ the number of cycles, $\mathrm{R}$ the ratio of the minimum 115 static and cyclic tests (8 specimens tested at $70 \%$
91 stress to the maximum stress $\left(R=\sigma_{\text {Min }} / \sigma_{M a x}\right)$,

92 parameter $\mathrm{A}$ is set to 1 , parameter $\mathrm{B}$ is set to 0.04

93 and $\mathrm{C}$ is the correction factor.

94 Tomor and Verstrynge [6] identified three stages of

95 fatigue deterioration with the use of an acoustic

96 emission technique to monitor the response of

97 masonry prisms under long-term fatigue in

98 compression. During the first stage $(0-75 \%$ of the

99 total number of cycles), the acoustic emission

100 levels were relatively low and constant. A small

101 increase in emission was observed in the second

102 stage (75-95\% cycles), followed by rapid increase

103 in emission and sudden failure during the third

104 stage $(95-100 \%$ cycles $)$.

105 Tomor et al. [8] also identified three distinct stages

106 of fatigue deterioration based on acoustic emission

107 levels. During Stage I, reduction in emission was

108 observed $(0-32 \%$ of the total loading cycles for

109 compression and 0-58\% for shear). During Stage

110 II, emission stabilised (32-67\% for compression,

111 not evident in shear) and in Stage III rapid increase

112 in emission was observed, leading to failure $(67-$

$113100 \%$ for compression, $58-100 \%$ shear). 
116

stress) on brick masonry specimens and walls and

117 suggested a $\varepsilon$-N curve (strain vs. number of cycles)

118 with three distinctive stages. During Stage

119 deformations increased rapidly for the first $10 \%$ of

120 loading cycles, during Stage II deformation

121 increased at a constant rate $(10-80 \%$ of loading

122 cycles) and during Stage III deformations increased

123 rapidly again, leading to failure. Carpinteri et al.

124 [9] also related the rate of change in vertical

125 deformation during Stage II $\left(\vartheta \varepsilon_{v} / \vartheta n\right)$ to the number

126 of cycles at failure ( $\mathrm{N}_{\mathrm{f}}$ cycles) as shown in Equation

$127 \quad 1.4$

$$
N_{f}=a\left(\frac{\vartheta \varepsilon_{v}}{\vartheta n}\right)^{b}
$$

128 Where $\varepsilon_{\mathrm{v}}$ is the vertical deformation, $\mathrm{n}$ is the

129 number of cycles and $\mathrm{N}_{\mathrm{f}}$ is the number of loading

130 cycles at failure. Parameters $a$ and $b$ are material

131 constants, that can be evaluated experimentally by

132 applying a number of loading cycles on a prism up

133 to the point here deformation starts to increase at a

134 constant rate (over $10 \%$ of the fatigue life).

135 There are conflicting results for the different stages

136 of fatigue for masonry and a lack of experimental

137 data for identifying appropriate $\mathrm{SN}$ curves for

138 different types of masonry and the evolution of

139 strain under fatigue loading. The aim of this study
140 is to i) investigate the stages of fatigue 141 deterioration, ii) investigate the evolution of strain 142 and stress-strain curves and iii) provide test data to 143 develop mathematical models to predict the fatigue 144 life of masonry.

146 2. Quasi-static and long-term cyclic tests

\section{7 under compression}

148 Based on the work of Roberts et al. [5] and Tomor 149 et al. [8], a series of brick masonry prisms have 150 been tested under quasi-static and long-term cyclic 151 compressive loading to identify changes in the 152 material properties of masonry.

\subsection{Materials}

154 The experimental study intends to represent the 155 weakest form of masonry, widely found in the UK 156 waterways network, originating from the 1750 s157 1850s. Brick masonry prisms were built using 158 handmade low-strength solid 210x100x65 mm 159 Michelmersh bricks (B1 bricks). The average 160 compressive strength of the bricks was $4.86 \mathrm{~N} / \mathrm{mm}^{2}$ $161\left(1.19 \mathrm{~N} / \mathrm{mm}^{2}\right.$ standard deviation (SD) and $24.48 \%$ 162 coefficient of variation) and the gross dry density $1631823 \mathrm{~kg} / \mathrm{m}^{3}$. Lime-mortar with 0:1:2 cement: lime: 164 sand by volume (M01 mortar) was used with 
165

NHL3.5 lime and $3 \mathrm{~mm}$ sharp washed sand and the

166 mortar joins were $8 \mathrm{~mm}$ thick.

1672.2 Test specimens

168 Small-scale masonry prisms (B1M01) comprised

169 of five stack-bonded bricks with four $8 \mathrm{~mm}$ mortar

170 joints built according to the ASTM standards

171 (ASTM, 2014) with total dimensions of $210 \times 100$

$172 \times 357 \mathrm{~mm}^{3}$ (Figure 2-1). In order to have systematic

173 building quality, the same experienced master

174 stonemason constructed all specimens.

175 Specimens were cured at room temperature for a

176 minimum of five days, stored outdoors for a

177 maximum of six months and acclimatised for a

178 minimum of three days at room temperature prior

179 to testing (Oliveira et al., 2006).

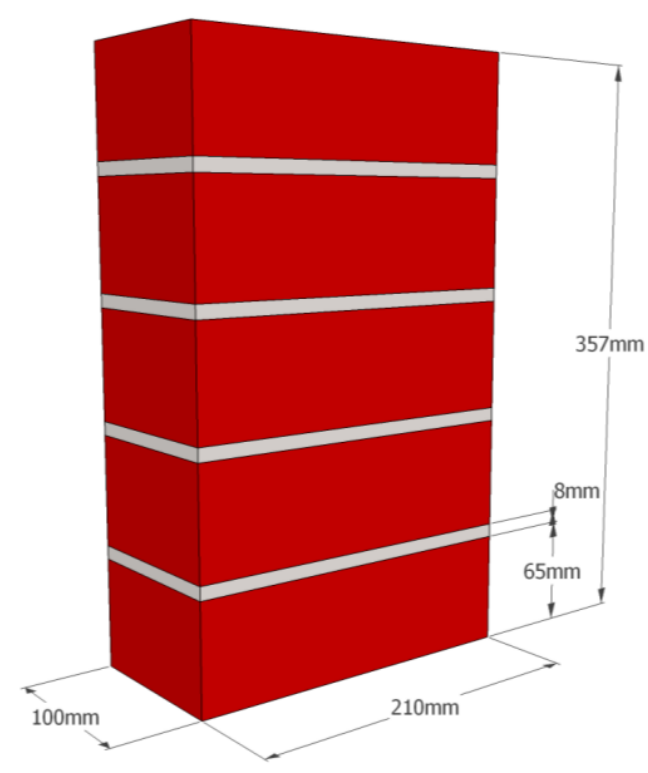

180

181 Figure 2-1 Masonry prism dimensions

\subsection{Test setup, preparation and instrumentation}

183 Specimens were tested under compression using a

$184250 \mathrm{kN}$ actuator. Deflections were monitored using

185 four Linear Variable Differential Transformers

186 (LVDTs) with $\pm 5 \mathrm{~mm}$ linear range and $0.07 \%$

187 accuracy. Two LVDTs were attached at the front

188 and two in the back of the prisms (Figure 2-2).

189 LVDTs were positioned at $10 \mathrm{~mm}$ distance from

190 the edges of the prisms and set against wooden

191 blocks (Tomor \& Verstrynge, 2013; Tomor et al.,

192 2013). The distance between the wooden blocks

193 and the LVDTs was ca. $81 \mathrm{~mm}$ and included two

194 mortar joints ( $8 \mathrm{~mm}$ each) and one brick $(65 \mathrm{~mm})$.

195 The upper and lower surfaces of the prisms were

196 brushed to remove loose particles and ground flat

197 prior to the test (Oliveira et al., 2006; ASTM,

198 2014). Prisms were placed, subsequently, between

199 layers of $3 \mathrm{~mm}$ plywood and $30 \mathrm{~mm}$ steel plates to

200 ensure effective load distribution and to reduce

201 localised stress concentrations (Tomor \&

202 Verstrynge, 2013; Tomor et al., 2013). 
Figure 2-2 Instrumentation of prisms

205

2062.4 Loading

207 Three sets of tests were performed under quasi-

208 static and fatigue loading to identify material

209 properties and to investigate changes in the

210 material during high-cycle compressive fatigue

211 loading of masonry prisms.

212 - Quasi-Static tests. A set of six prisms were

213 tested under displacement-controlled quasi-static

214 compression to obtain the mean compressive

215 strength of the material. Loading was applied at

$2160.01 \mathrm{~mm} / \mathrm{sec}$ rate of displacement to obtain the full

217 stress-strain curve.

218 - Fatigue tests - Type I. Masonry prisms

219 were tested under long-term compressive cyclic

220 loading at $2 \mathrm{~Hz}$ frequency to identify the number of
221 cycles to failure at different stress levels. Before

222 the start of the fatigue tests, quasi-static loading

223 was applied up to the mean fatigue load. Fatigue

224 loading was subsequently applied in a sinusoidal

225 pattern (Figure 2-3), between defined minimum

226 and maximum stress levels.

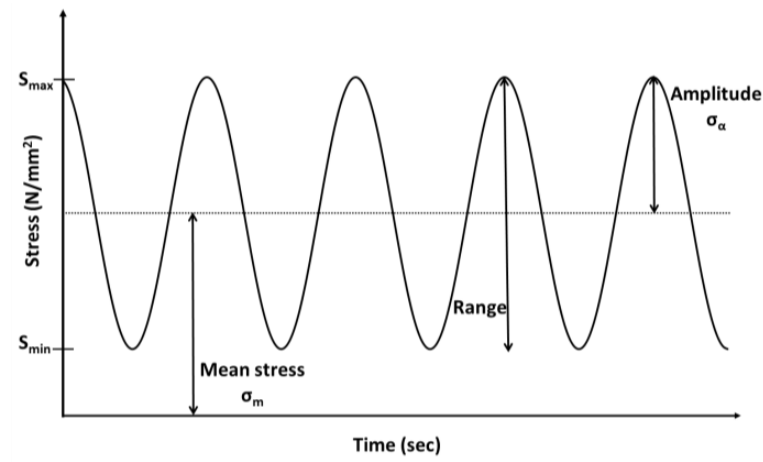

228 Figure 2-3 Sinusoidal load pattern for Type I fatigue tests

229 The minimum (Smin) and maximum (Smax) stress

230 levels were expressed as percentage of the mean 231 ultimate quasi-static strength. The minimum stress

232 represent the dead load of the structure due to its

233 self-weight and was set to $10 \%$ of the ultimate

234 compressive strength to enable the most extreme

235 range of fatigue loading to be applied.

236 The maximum stress level represents live load (e.g.

237 similar to traffic over a masonry arch bridge) and

238 ranged between $55 \%$ and $80 \%(55 \%, 60 \%, 68 \%$,

$23980 \%$ ) of the ultimate compressive strength for the 240 individual specimens. 
242 fatigue tests was designed to identify stages during

243 fatigue deterioration and evolution of the stress-

244 strain curves. Loading was first applied statically

245 up to the mean fatigue stress level $\sigma_{\mathrm{m}}$ under

246 displacement control at a $0.01 \mathrm{~mm} / \mathrm{sec}$ loading rate

247 (Branch A, Figure 2-4), cycled sinusoidally

248 between the minimum and maximum load levels

249 for 1000 cycles (Branch B, Figure 2-4) and

250 unloaded (Branch C, Figure 2-4). The process was

251 repeated until failure occurred. Branch A was used

252 to identify the stress-strain relationship, up to the

253 mean fatigue stress level, every 1000 cycles during

254 the fatigue life of the prisms. Similarly to Type I

255 fatigue tests, the minimum stress level was set to

$25610 \%$ of the compressive strength and the maximum

257 stress level was set to $63 \%, 68 \%$ and $73 \%$ for the

258 individual specimens.

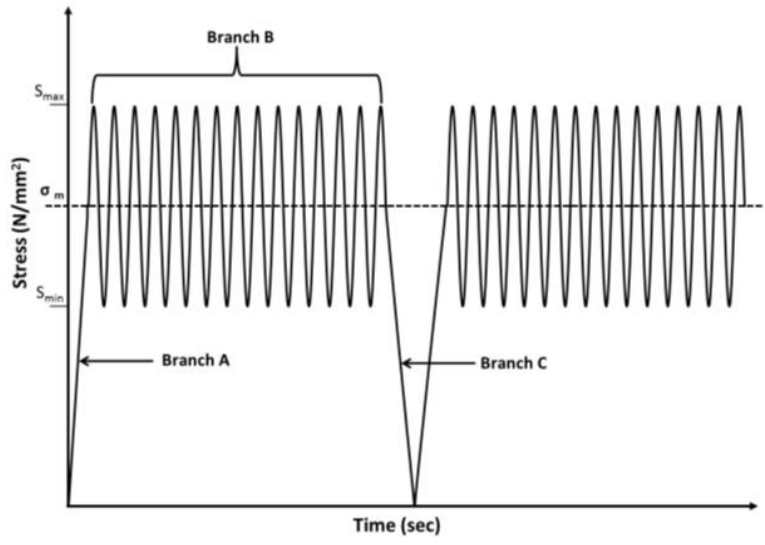

260 Figure 2-4 Load pattern for Type II fatigue tests 261 (Branch A quasi-static loading, Branch B cyclic loading, 262 Branch C unloading)

263

264 3. Results

2653.1 Quasi-static tests

266 The mean compressive strength for the set of 267 B1M01 prisms tested, according to BS EN 1052$2681: 1999$, was $2.94 \mathrm{~N} / \mathrm{mm}^{2}\left(\mathrm{SD} 0.10 \mathrm{~N} / \mathrm{mm}^{2}\right)$. During 269 quasi-static compression vertical cracks developed 270 initially around the middle of the specimens and 271 subsequently on the narrow sides, leading to failure 272 (Figure 3-1).

273 3.2 Fatigue Tests - Type I.

274 A total of 32 prisms were tested to failure under 275 maximum stress levels of $55,60,68$ or $80 \%$ of the 276 average quasi-static compressive strength (see 277 section 2.4). The maximum number of loading 278 cycles was recorded and shown in Table 3-1. 
Table 3-1 Fatigue test results - Type I

\begin{tabular}{|l|r|r|r||l|r|r|r|}
\hline $\begin{array}{c}\text { S pecimen } \\
\text { Name }\end{array}$ & $\begin{array}{c}\text { Load range } \\
(\mathbf{k N})\end{array}$ & $\begin{array}{c}\text { Stress } \\
\text { Range } \\
\left(\mathbf{N} / \mathbf{m m}^{2}\right)\end{array}$ & $\mathbf{N}$ & $\begin{array}{l}\text { S pecimen } \\
\text { Name }\end{array}$ & $\begin{array}{l}\text { Load range } \\
(\mathbf{k N})\end{array}$ & $\begin{array}{c}\text { S tress } \\
\text { Range } \\
\left(\mathbf{N} / \mathbf{m m}^{2}\right)\end{array}$ & $\mathbf{N}$ \\
\hline B1M01-18 & $6-49$ & $0.29-2.33$ & 2,566 & B1M01-57 & $6-42$ & $0.29-2.00$ & 1,100 \\
\hline B1M01-48 & $6-49$ & $0.29-2.33$ & 14,073 & B1M01-26 & $6-37$ & $0.29-1.76$ & 25,342 \\
\hline B1M01-49 & $6-49$ & $0.29-2.33$ & 2,832 & B1M01-28 & $6-37$ & $0.29-1.76$ & $2,646,302$ \\
\hline B1M01-50 & $6-49$ & $0.29-2.33$ & 456 & B1M01-29 & $6-37$ & $0.29-1.76$ & 122,762 \\
\hline B1M01-19 & $6-42$ & $0.29-2.00$ & 1,800 & B1M01-30 & $6-37$ & $0.29-1.76$ & $1,268,627$ \\
\hline B1M01-20 & $6-42$ & $0.29-2.00$ & 3,600 & B1M01-31 & $6-37$ & $0.29-1.76$ & $3,528,118$ \\
\hline B1M01-21 & $6-42$ & $0.29-2.00$ & 13,000 & B1M01-32 & $6-37$ & $0.29-1.76$ & 986,325 \\
\hline B1M01-22 & $6-42$ & $0.29-2.00$ & 17,350 & B1M01-33 & $6-37$ & $0.29-1.76$ & 796,744 \\
\hline B1M01-23 & $6-42$ & $0.29-2.00$ & 18,651 & B1M01-34 & $6-34$ & $0.29-1.62$ & 56,562 \\
\hline B1M01-24 & $6-42$ & $0.29-2.00$ & 18,276 & B1M01-40 & $6-34$ & $0.29-1.62$ & 412,774 \\
\hline B1M01-35 & $6-42$ & $0.29-2.00$ & 3,000 & B1M01-41 & $6-34$ & $0.29-1.62$ & $1,088,560$ \\
\hline B1M01-36 & $6-42$ & $0.29-2.00$ & 6,737 & B1M01-43 & $6-34$ & $0.29-1.62$ & 2,200 \\
\hline B1M01-53 & $6-42$ & $0.29-2.00$ & 134 & B1M01-44 & $6-34$ & $0.29-1.62$ & 4,864 \\
\hline B1M01-54 & $6-42$ & $0.29-2.00$ & 3,541 & B1M01-45* & $6-34$ & $0.29-1.62$ & $10,225,676$ \\
\hline B1M01-55 & $6-42$ & $0.29-2.00$ & 5,994 & B1M01-46 & $6-34$ & $0.29-1.62$ & $1,724,587$ \\
\hline B1M01-56 & $6-42$ & $0.29-2.00$ & 212 & B1M01-47 & $6-34$ & $0.29-1.62$ & $1,672,237$ \\
\hline * No failure, testing discontinued & & & & & \\
\hline
\end{tabular}

281 The failure patterns under fatigue loading were

282 very similar to quasi-static loading with vertical

283 splitting cracks along the middle of the specimens,

284 leading to failure (Figure 3-1).

285 Results of the quasi-static and fatigue compression

286 tests are shown in Figure 3-2 together with

287 proposed SN relationships by Casas [2] and Tomor

288 \& Verstrynge [6]. Quasi-static test results are

289 included as failure at 1 cycle. The SN relationship

290 by Casas [2] gives a good indication of the mean

291 number of cycles at each stress level, while the

292 relationship by Tomor and Verstrynge [6]

293 incorporates the quasi-static test results, although

294 slightly overestimates the mean number of cycles.

(a)

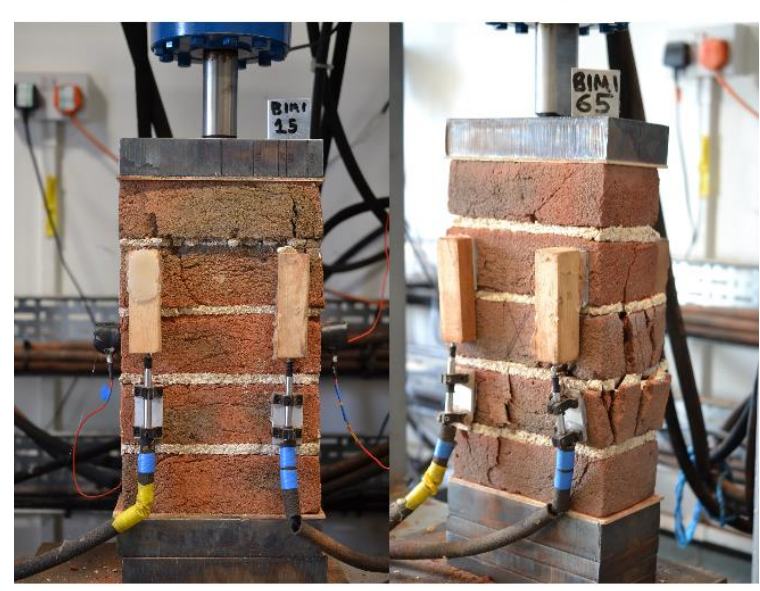

295

296 Figure 3-1 Typical failure pattern under (a) quasi-static

297 compression and (b) fatigue compression 


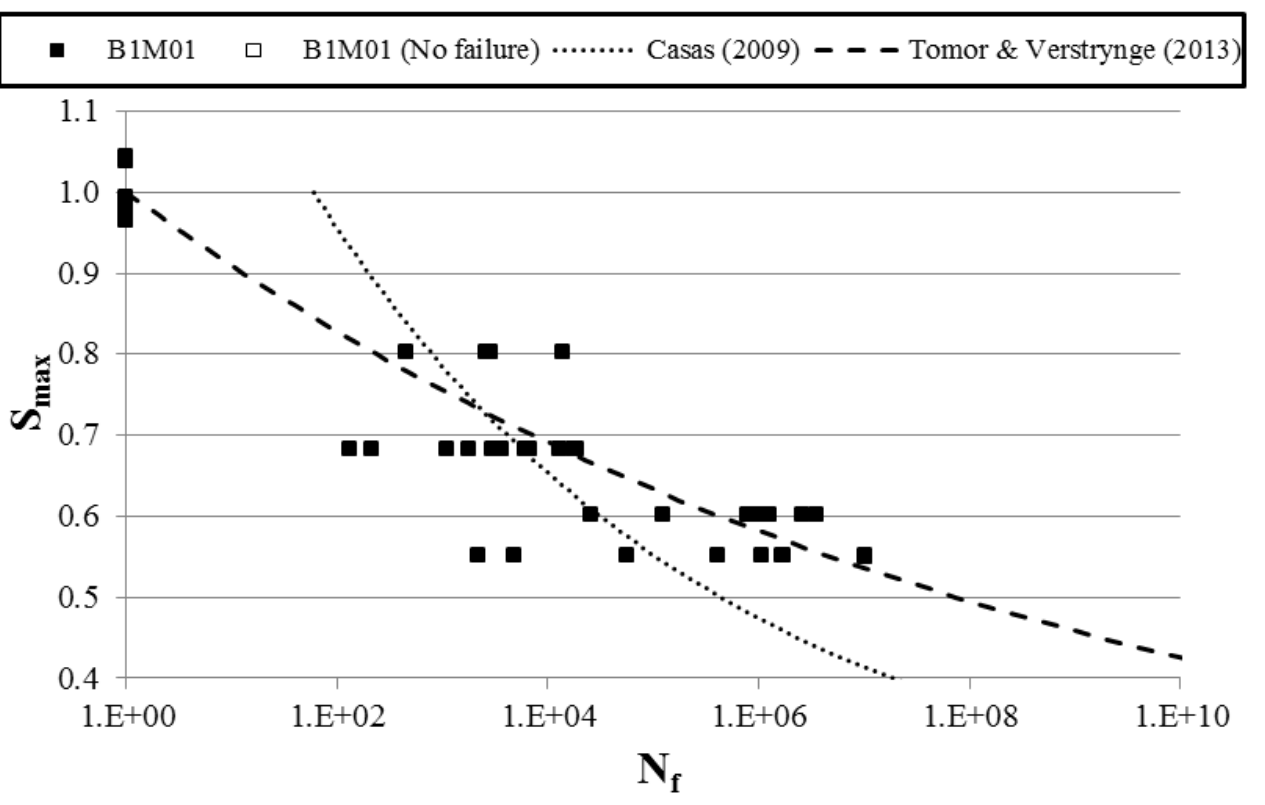

299 Figure 3-2 Fatigue test data together with SN curves [2, 6].

300 During the Type I Fatigue tests, maximum and 314 Stage III: rapid increase of strain during the last

301 minimum total longitudinal displacements were 315 10-20\% of life expectancy, caused by coalition of

302 recorded and the strain evolution curves $\left(\varepsilon-\mathrm{N} / \mathrm{N}_{\mathrm{f}}\right) 316$ micro-cracks into macro-cracks and leading to

303 plotted for each stress level in Figure 3-3 to Figure 317 failure.

304 3-6 (for 55, 60, 68, 80\% maximum stress

305 respectively). The $\varepsilon-\mathrm{N}$ curves exhibit a typical $\mathrm{S}$

306 shape (Holmen, 1982; Carpinteri et al., 2014), with

307 three distinct stages:

318 Carpinteri et al. [9] indicated that Stage II lasts

319 until $80 \%$ of the fatigue life of masonry based on

320 limited tests under $70 \%$ stress, while according to

321 the data presented here, Stage II occupies the range

308 Stage I: rapid increase of strain during the first

322 between $10 \%$ and $90 \%$ of the total loading cycles

$30910 \%$ of the life expectancy, caused by initiation of

323 sustained by a prism at different stress levels.

310 micro-cracks.

324 Carpinteri et al. [9] proposed the use of equation

311 Stage II: reveals a gradual increase of strain for

312 approximately $80 \%$ of the total number of cycles,

313 caused by development of micro-cracks.

3251.4 to correlate the vertical deformation with the 326 number of cycles. The strain evolution could be 327 more precisely described by three distinct 328 equations (parabolic type for stage I and Stage III 
329 and linear type for stage II) for the different fatigue

330 stages that would consider the effect of stress level.

(a)

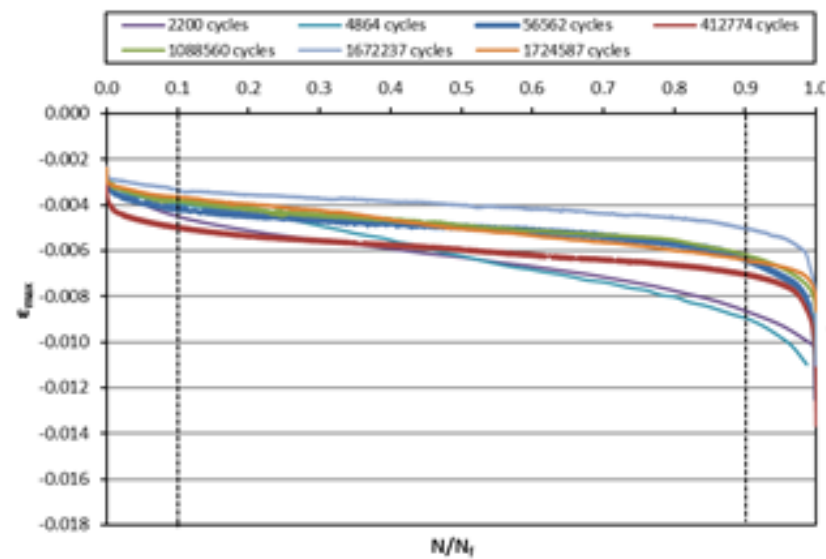

(b)

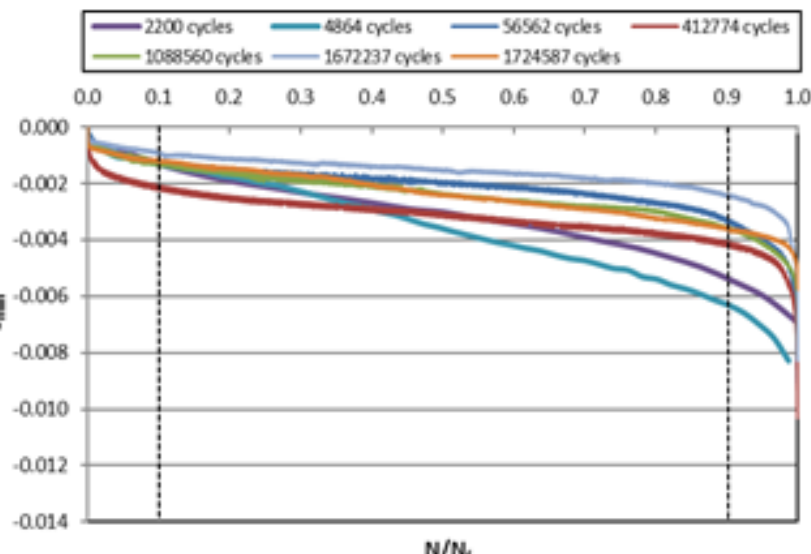

332 Figure 3-3 Total longitudinal strain variation with the cycle ratio for 55\% maximum stress level (a) maximum total strain,

333 (b) minimum total strain

(a)

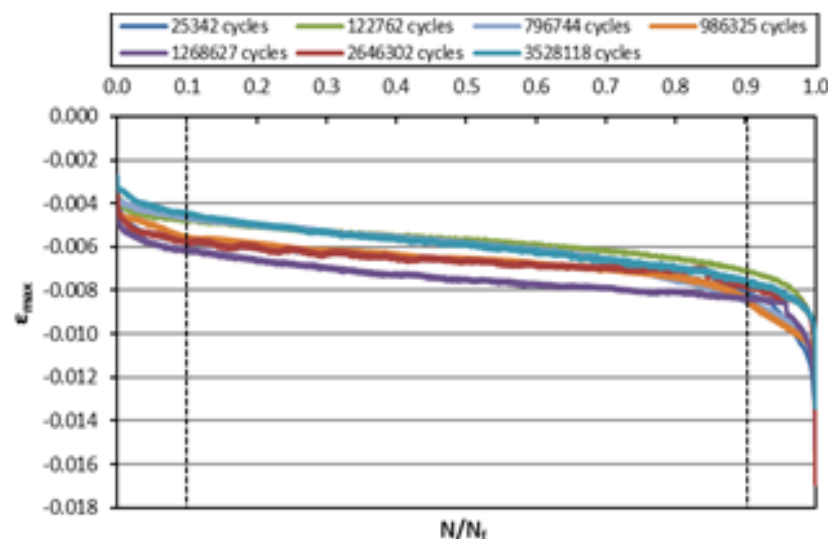

(b)

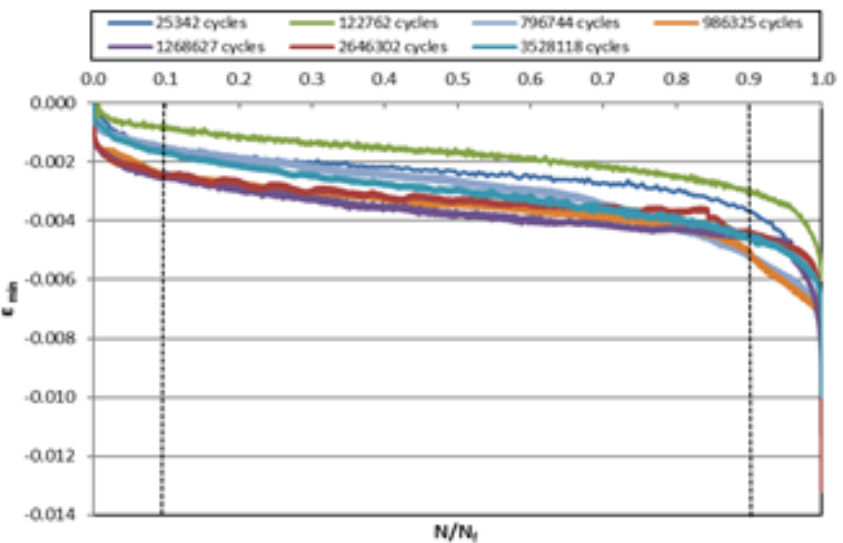

336 Figure 3-4 Total longitudinal strain variation with the cycle ratio for 60\% maximum stress level (a) maximum total strain,

337 (b) minimum total strain 
(a)

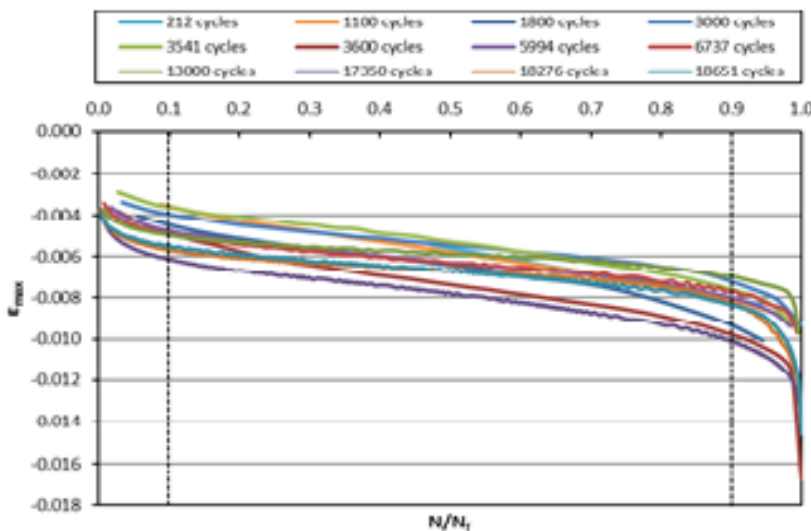

(b)

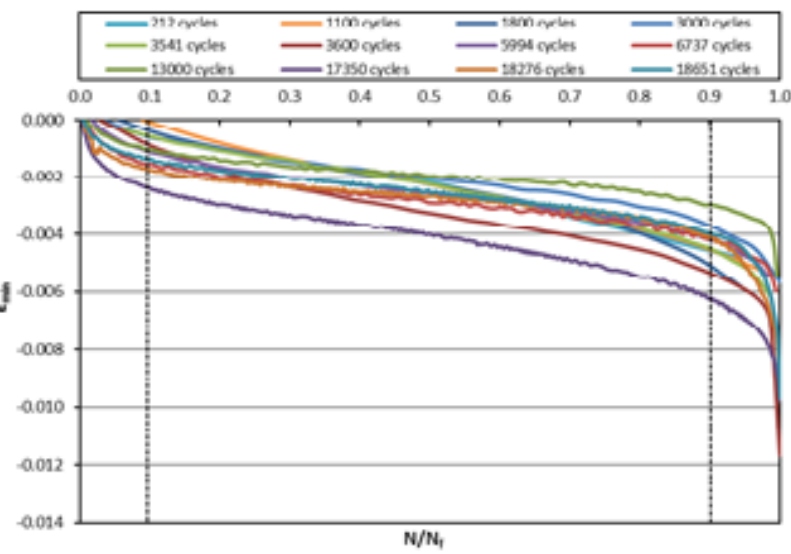

Figure 3-5 Total longitudinal strain variation with the cycle ratio for $68 \%$ maximum stress level (a) maximum total strain,

(a)

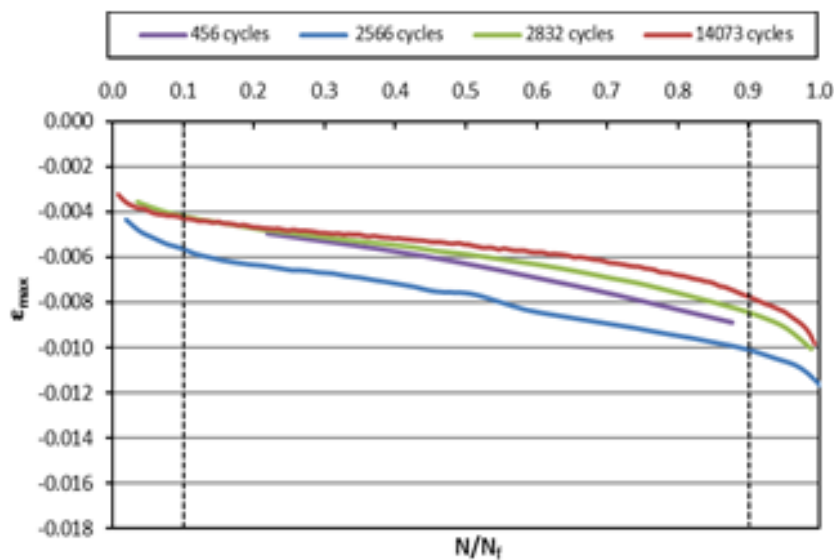

(b)

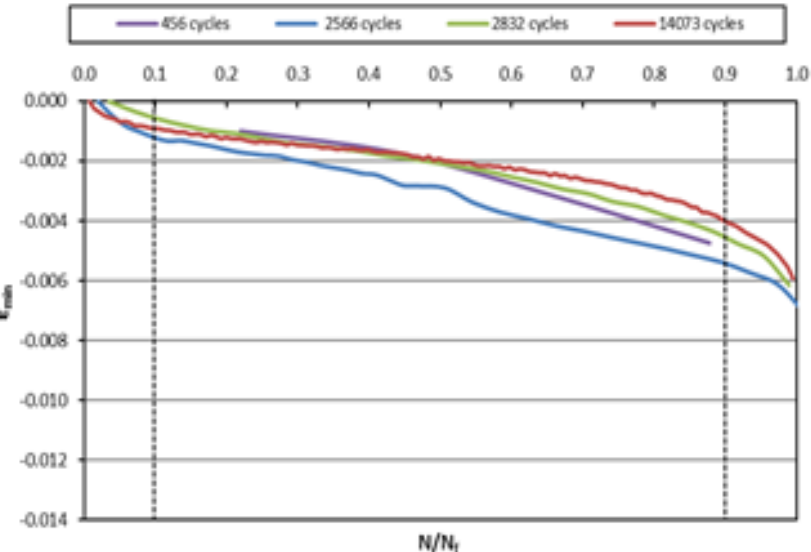

343 Figure 3-6 Total longitudinal strain variation with the cycle ratio for $80 \%$ maximum stress level (a) maximum total strain,

344 (b) minimum total strain

345 Three stages of strain development have already

346 been identified in concrete under fatigue loading

347 (Holmen, 1982; Kim \& Kim, 1996; Breitenbucher 348 \& Ibuk, 2006; Zanuy et al., 2011) and also for 353 80\%). This indicates a faster rate of the fatigue

349 masonry (Carpinteri et al., 2014).

350 The rate of strain evolution at Stage II is noticeably 351 steeper for higher stress levels (as shown in Figure 352 3-7 for maximum stress levels $55 \%, 60 \%, 68 \%$ and 
355 failure of the specimen.

369 stress

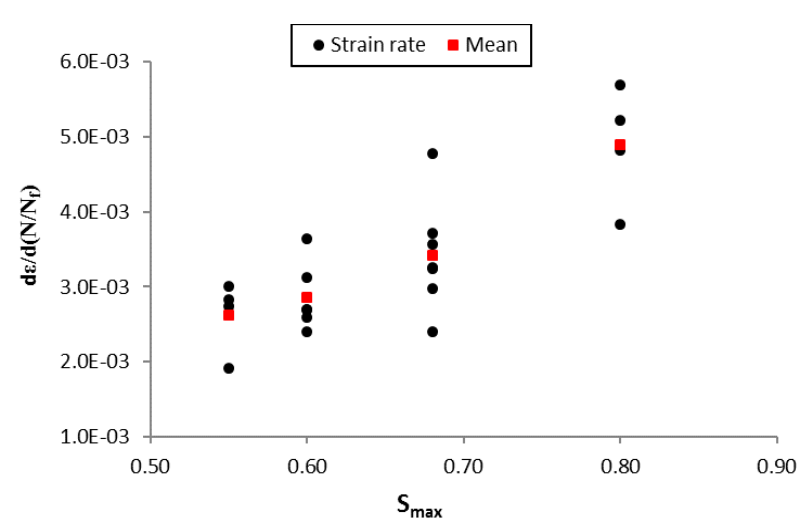

356

\begin{tabular}{|l|r|r|r|}
\hline $\begin{array}{c}\text { Specimen } \\
\text { Name }\end{array}$ & $\begin{array}{c}\text { Load } \\
\text { Range } \\
(\mathbf{k N})\end{array}$ & $\begin{array}{c}\text { Stress } \\
\text { Range } \\
\left(\mathbf{N} / \mathbf{m m}^{2}\right)\end{array}$ & \multicolumn{1}{|c|}{$\mathbf{~}$} \\
\hline B1M01-58 & $6-42$ & $0.29-2.00$ & 31,000 \\
\hline B1M01-59 & $6-42$ & $0.29-2.00$ & 69,537 \\
\hline B1M01-60 & $6-42$ & $0.29-2.00$ & 34 \\
\hline B1M01-61 & $6-42$ & $0.29-2.00$ & 71,342 \\
\hline B1M01-62 & $6-42$ & $0.29-2.00$ & 11,754 \\
\hline B1M01-63 & $6-42$ & $0.29-2.00$ & 37,938 \\
\hline B1M01-64 & $6-42$ & $0.29-2.00$ & 33,752 \\
\hline B1M01-65 & $6-42$ & $0.29-2.00$ & 275,000 \\
\hline
\end{tabular}

357 Figure 3-7 Strain rate $\left(\mathrm{d} \varepsilon / \mathrm{d}\left(\mathrm{N} / \mathrm{N}_{\mathrm{f}}\right)\right)$ for $55 \%, 60 \%, 68 \%, 371$

$35880 \%$ maximum stress during Stage II Fatigue test - Type 359 I

3603.3 Fatigue tests - Type II

361 Masonry prisms were tested under $73 \%, 68 \%$ and

362 63\% maximum compressive stress during Type II

363 fatigue tests (see Section 2.4) and results listed in

364 Table 3-2 to Table 3-4.

365 Table 3-2 Fatigue test results - Type II, 73\% maximum

366 stress

\begin{tabular}{|l|r|r|r|}
\hline $\begin{array}{l}\text { Specimen } \\
\text { Name }\end{array}$ & $\begin{array}{c}\text { Load } \\
\text { Range } \\
(\mathbf{k N})\end{array}$ & $\begin{array}{c}\text { Stress } \\
\text { Range } \\
\left(\mathbf{N} / \mathbf{m m}^{2}\right)\end{array}$ & N \\
\hline B1M01-66 & $6-45$ & $0.29-2.14$ & 253 \\
\hline B1M01-67 & $6-45$ & $0.29-2.14$ & 200 \\
\hline B1M01-68 & $6-45$ & $0.29-2.14$ & 413 \\
\hline B1M01-69 & $6-45$ & $0.29-2.14$ & 53 \\
\hline B1M01-70 & $6-45$ & $0.29-2.14$ & 55 \\
\hline B1M01-76 & $6-45$ & $0.29-2.14$ & 7 \\
\hline B1M01-77 & $6-45$ & $0.29-2.14$ & 104 \\
\hline B1M01-78 & $6-45$ & $0.29-2.14$ & 240 \\
\hline B1M01-85 & $6-45$ & $0.29-2.14$ & 93 \\
\hline
\end{tabular}

372 Table 3-4 Fatigue test results - Type II, 63\% maximum

373 stress

\begin{tabular}{|l|r|r|r|}
\hline $\begin{array}{c}\text { S pecimen } \\
\text { Name }\end{array}$ & $\begin{array}{c}\text { Load } \\
\text { Range } \\
(\mathbf{k N})\end{array}$ & $\begin{array}{c}\text { Stress } \\
\text { Range } \\
\left(\mathbf{N} / \mathbf{m m}^{2}\right)\end{array}$ & $\begin{array}{c}\text { Number of } \\
\text { cycles }\end{array}$ \\
\hline B1M01-71 & $6-39$ & $0.29-1.86$ & 718 \\
\hline B1M01-72 & $6-39$ & $0.29-1.86$ & 11,038 \\
\hline B1M01-73 & $6-39$ & $0.29-1.86$ & 269 \\
\hline B1M01-74 & $6-39$ & $0.29-1.86$ & 2,515 \\
\hline B1M01-75 & $6-39$ & $0.29-1.86$ & 1,104 \\
\hline B1M01-79 & $6-39$ & $0.29-1.86$ & 266 \\
\hline B1M01-80 & $6-39$ & $0.29-1.86$ & 19,203 \\
\hline B1M01-81 & $6-39$ & $0.29-1.86$ & 54 \\
\hline B1M01-82 & $6-39$ & $0.29-1.86$ & 34,728 \\
\hline B1M01-83 & $6-39$ & $0.29-1.86$ & 3,355 \\
\hline B1M01-84 & $6-39$ & $0.29-1.86$ & 256 \\
\hline B1M01-86 & $6-39$ & $0.29-1.86$ & 59,921 \\
\hline B1M01-87 & $6-39$ & $0.29-1.86$ & 543 \\
\hline B1M01-88 & $6-39$ & $0.29-1.86$ & 4,809 \\
\hline B1M01-89 & $6-39$ & $0.29-1.86$ & 881 \\
\hline
\end{tabular}

376 Evolution of the stress-strain curves for $68 \%$ and

$37763 \%$ maximum stress identified every 1000 cycles 
378 (every 500 cycles for B1M01-83 and B1M01-88)

379 are shown in Figure 3-8 and Figure 3-9. No stress-

380 strain curve could be identified for $73 \%$ stress due

381 to rapid deterioration and failure under 300 cycles.

382 The stress-strain curve is straight initially (or

383 slightly concave towards the strain axis) and

384 becomes convex and increasingly curved for

385 increasing load cycles. The residual strain is large

386 in Stage I, decreases and stabilises in Stage II and

387 increases fast again in Stage III. Concrete exhibits

388 similar behaviour under fatigue loading $[10,11]$.

389

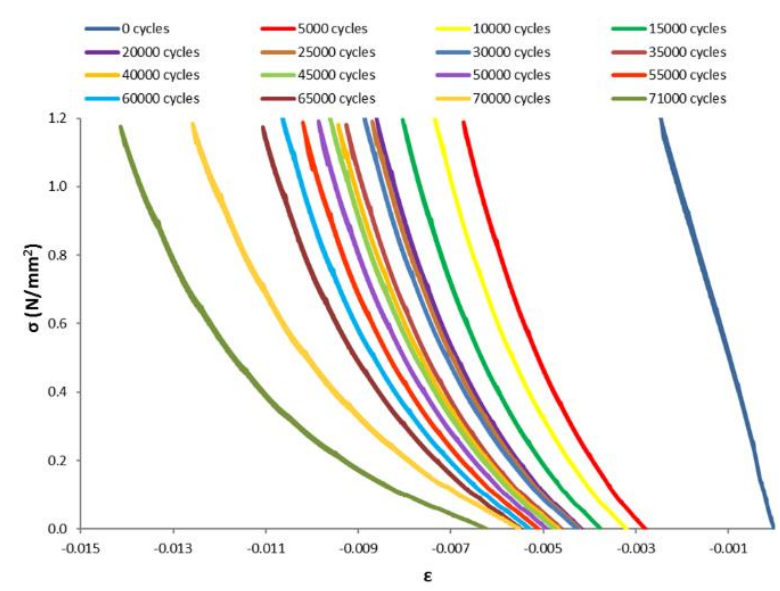

391 Figure 3-8 Stress-strain curve development every 1000

392 cycles under 68\% maximum stress (B1M01-61)

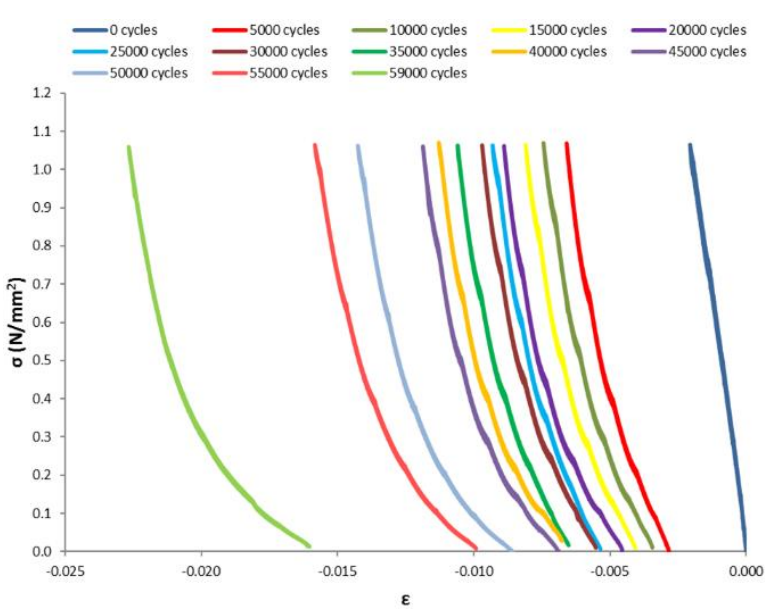

394 Figure 3-9 Stress-Strain curve development every 1000 cycles 395 under 63\% maximum stress (B1M01-86)

396 It is noteworthy that the maximum recorded strains 397 at failure, during quasi-static compressive tests are 398 noticeably lower compared to respective strains 399 under fatigue loading. Thus, prior cyclic loading of 400 a masonry prism imposes additional deformation.

401 The maximum strain at failure is the lowest under 402 quasi-static loading (0.002-0.005; mean 0.003; SD 403 0.001) and increases for lower fatigue stress levels 404 (0.005-0.018; mean 0.012; SD 0.005 for $68 \%$ 405 maximum stress and 0.017-0.025; mean 0.020; SD 4060.003 for $63 \%$ maximum stress). Increased strain 407 under lower fatigue stress levels is likely to be 408 associated with increasing effect of creep. For 409 extended test durations creep damage is 410 accumulated during the relatively longer time spent 411 near the peak stress of each cycle. 


\section{4. Discussion}

413 Masonry arch bridges are subjected to increasing

414 traffic loading and gradual material deterioration

415 due to environmental impact and fatigue loading.

416 Changes in the material properties have direct

417 influence on the load carrying capacity and rate of

418 deterioration of the overall structure. Very little

419 guidance is, however, available for estimating

420 changes in the material properties for masonry over

421 time. Test data will next be used to develop

422 mathematical models for the evolution of material

423 properties under fatigue compressive loading.

424 Mathematical models can in turn be used for

425 improved modelling of masonry under changing

426 load regimes and estimating the load-carrying

427 capacity over time to improve assessment,

428 maintenance and restoration masonry arch bridges.

429 The fatigue life of the structure can be evaluated by

430 available SN models [2, 6]. Past and future loading

431 history may be estimated using simplified load

432 models, e.g. Miner's Rule (Equation 4.1) [12] to

433 evaluate the residual service life.

$$
\frac{n_{1}}{N_{1}}+\cdots+\frac{n_{i-1}}{N_{i-1}}+\frac{n_{i}}{N_{i}}<1
$$

434 Where ni is the number of cycles at any stress range

435 and $\mathrm{Ni}$ is the number of cycles causing failure at

436 the corresponding stress range. Knowing the

437 number of cycles that the structure has experienced

438 an appropriate stress-strain curve can be selected

439 for the assessment of a masonry arch bridge (e.g.

440 using finite element models).

441 Changes in the deformability of a masonry arc 442 bridge under traffic loading, observed during 443 monitoring, can be associated with the 444 experimentally recorded $\varepsilon-\mathrm{N}$ curve configuration 445 and contribute to appropriate maintenance 446 planning. The configuration of the $\varepsilon-\mathrm{N}$ curve 447 indicates that strain changes with high rate and in 448 parabolic shape during stage I and III and linearly 449 at a constant rate during the second stage. An 450 observed sudden change during long-term 451 monitoring of a structure from linear growth of 452 strain to a non-linear trend could mean that the 453 structure is undergoing stage III and major 454 strengthening is required or traffic needs to be 455 diverted. 
457

\section{Conclusions}

458 This study presents test results from small-scale

459 laboratory tests on changes of the material

460 properties of masonry under compressive fatigue

461 loading.

462 Strain evolution curves $(\varepsilon-\mathrm{N})$ exhibit a typical ' $\mathrm{S}$ '

463 configuration with three distinct stages. During the

464 first stage $\left(10 \%\right.$ of $\mathrm{N}_{\mathrm{f}}$ ), strains grow rapidly

465 indicating initiation of micro-cracks. Stage II is the

466 dominant stage (10-90\% of $\mathrm{N}_{\mathrm{f}}$ ) during which the

467 strains grow steadily until Stage III $(90-100 \%$ of

$468 \mathrm{~N}_{\mathrm{f}}$ ), at which point, coalition of micro-cracks to

469 macro-cracks leads to sudden failure of the prism.

470 The rate of strain evolution in Stage II of the fatigue

471 life is lower for lower stress levels.

472 The configuration of the stress-strain curve

473 changes during cyclic compressive loading from

474 concave with respect to the strain axis to convex

475 with greater curvature for increased loading cycles.

476 Large initial change in the residual strain is

477 observed in Stage I, reduced and relatively constant

478 strain in Stage II and increases again in Stage III.

479 Prior cyclic loading of masonry imposes additional 480 deformation. The maximum strain at failure is 481 greater for lower fatigue stress levels, likely to be 482 due to the effect of creep for longer test durations.
483 Test data will be used to develop probability based

484 mathematical models for the evolution of material

485 properties under fatigue compressive loading.

486 Improved models for material properties will

487 enable enhanced modelling of masonry arch 488 bridges and estimation of the load carrying 489 capacity and remaining service life over time.

\section{Acknowledgement}

492 The work reported in this paper was supported by 493 the International Union of Railways (UIC). The 494 technical and financial support provided, is 495 gratefully acknowledged by the authors.

\section{References}

[1] S. Sustainable Bridges Project, "European Railway Bridge Demography, Deliverable D1.2 - Technical report," 2004.

[2] J. R. Casas, "A probabilistic fatigue strength model for brick masonry under compression," Construction and Building Materials, vol. 23, no. 8, pp. 2964-2972, 2009.

[3] D. P. Abrams, J. L. Noland and R. H. Atkinson, "Response of Clay-unit Masonry to Repeated Compressive Forces," Melbourne, Australia, 1985.

[4] G. Clark, "Bridge Analysis Testing and Cost Causation Project: Serviceability of Brick 
Masonry," British Rail Research Report No. LR-CES-151, 1994.

[5] T. Roberts, T. Hughes, V. Dandamudi and B. Bell, "Quasi-static and high cycle fatigue strength of brick masonry," Construction and Building Materials, vol. 20, no. 9, pp. 603614, 2006.

[6] A. Tomor and E. Verstrynge, "A joint fatigue-creep deterioration model for masonry with acoustic emission based damage assessment," Construction and Building Materials, vol. 43, no. 1, pp. 575588, 2013.

[7] J. R. Casas, "Reliability-based assessment of masonry arch bridges," Construction and Building Materials, vol. 25, no. 4, pp. 16211631, 2011.

[8] A. Tomor, S. De Santis and J. Wang, "Fatigue deterioration process of brick masonry," Journal of the International Masonry Society, vol. 26, no. 2, pp. 41-48, 2013.

[9] A. Carpinteri, A. Grazzini, G. Lacidogna and A. Manuello, "Durability evaluation of reinforced masonry by fatigue tests and acoustic emission technique," Structural Control and Health Monitoring, vol. 21, no. 6, pp. 950-961, 2014.

[10] J. Crumley and W. Kennedy, "Fatigue and Repeated-load Elastic Characteristics of Inservice Portland Cement Concrete," Center of highway research, The University of Texas, Texas, USA, 1977.

[11] J. O. Holmen, "Fatigue of concrete by constant and variable amplitude loading," ACI, vol. 75, no. 0, pp. 71-110, 1982.
[12] M. Miner, "Cumulative damage in fatigue," Journal of Applied Mechanics, vol. 67, pp. A159-A164, 1945.

[13] D. V. Oliveira, P. B. Lourenço and P. Roca, "Cyclic behaviour of stone and brick masonry under uniaxial compressive loading," Materials and Structures, vol. 39, no. 2, pp. 247-257, 2006.

[14] P. Ronca, A. Franchi and P. Crespi, "Structural failure of historic buildings: masonry fatigue tests for an interpretation model," Structural Analysis of Historical Constructions, vol. 2, no. 1, pp. 273-279, 2004.

[15] C. Zanuy, L. Albajar and P. de la Fuente, "The fatigue process of concrete and its structural influence," Materiales de Construccion, vol. 61, no. 303, pp. 385-399, 2011.

[16] ASTM, "Standard test method for compressive strength of masonry prisms," in Annual Book of ASTM Standards, vol. 4.05, ASTM, Ed., West Conhohocken, ASTM International, 2014, pp. 889-895.

[17] R. Breitenbucher and H. Ibuk, "Experimentally based investigations on the degradation-process of concrete under cyclic loading," Materials and Structures, vol. 39, no. 7, pp. 717-724, 2006.

[18] J. Kim and Y. Kim, "Experimental study of the fatigue behavior of high strength concrete," Cement and Concrete Research, vol. 26, no. 10, pp. 1513-1523, 1996.
497

498 